\title{
Hidradenitis Suppurativa: Disease Burden and Etiology in Skin of Color
}

\author{
Dylan E. Lee $^{\mathrm{a}}$ Ashley K. Clark ${ }^{\mathrm{b}}$ Vivian Y. Shi ${ }^{\mathrm{c}}$ \\ ${ }^{a}$ Creighton University School of Medicine, Omaha, NE, USA; ${ }^{b}$ University of California Davis School of Medicine, \\ Sacramento, CA, USA; ' Division of Dermatology, Department of Medicine, University of Arizona, Tucson, AZ, USA
}

\section{Keywords \\ Hidradenitis suppurativa · Disease burden · Skin of color}

\begin{abstract}
Hidradenitis suppurativa (HS) is a chronic, debilitating skin disease. Although most studies on HS are conducted in largely Caucasian populations, evidence demonstrates a higher prevalence in patients with skin of color, including African and Hispanic populations. These racial subgroups are likely at risk for greater disease burden due to a higher prevalence of components of the metabolic syndrome, comorbid depression, and low socioeconomic status; however, there is a paucity of research in these populations. Additionally, studies examining the genetic and anatomical basis for $\mathrm{HS}$, as well as the response to HS therapies, are lacking for patients with skin of color. Complicating this issue is the limited access to effective medical care, including dermatologists, for African and Hispanic populations as well as other minority groups. In this review, we identify gaps in the knowledge base, highlight the association between $\mathrm{HS}$ and patients with skin of color, and provide direction for much needed research into this condition. @ $2018 \mathrm{~S}$. Karger AG, Basel
\end{abstract}

\section{Introduction}

Hidradenitis suppurativa (HS), also known as acne inversa, is a chronic, inflammatory skin disease that presents with painful and often malodorous abscesses, nod- ules, sinus tracts, and scar formation, usually involving apocrine gland-bearing skin in the axillae, inguinal region, and perianal and perineal regions [1]. The pathogenesis of HS is thought to involve follicular hyperkeratosis with subsequent occlusion and dilatation of the hair follicle, leading to rupture, inflammation, abscess formation, and, despite possible disease remission, dermal contractures and disfiguring scars (Fig. 1) [1].

Risk factors for HS include cigarette smoking, obesity, and metabolic syndrome (MetS) [2,3]. Although the prevalence of HS varies (from 0.00033 to $4.1 \%$ ), studies have reported an increased prevalence in African and Hispanic populations, as well as in women $[4,5]$. The disease burden of HS is largely due to a profound physical and psychological impact, which leads to depression and impaired quality of life (QoL) [6, 7]. Additionally, there are reports of HS being more common in individuals of low socioeconomic status (SES) [8].

The majority of the published studies on HS include largely Caucasian cohorts [9]. This may not represent the true prevalence of HS with respect to different racial subgroups, both internationally and in different regions of the USA [10]. More significantly, evidence demonstrates an increased prevalence of HS in individuals with skin of color (SOC); however, there is insufficient research to adequately assess the severity, comorbidities, genetic basis, and response to treatment in these populations (Table 1). In this review, we identify these knowledge gaps, underline the association between HS and minority populations, and provide directions for future research in this

\section{KARGER}

(c) 2018 S. Karger AG, Basel 


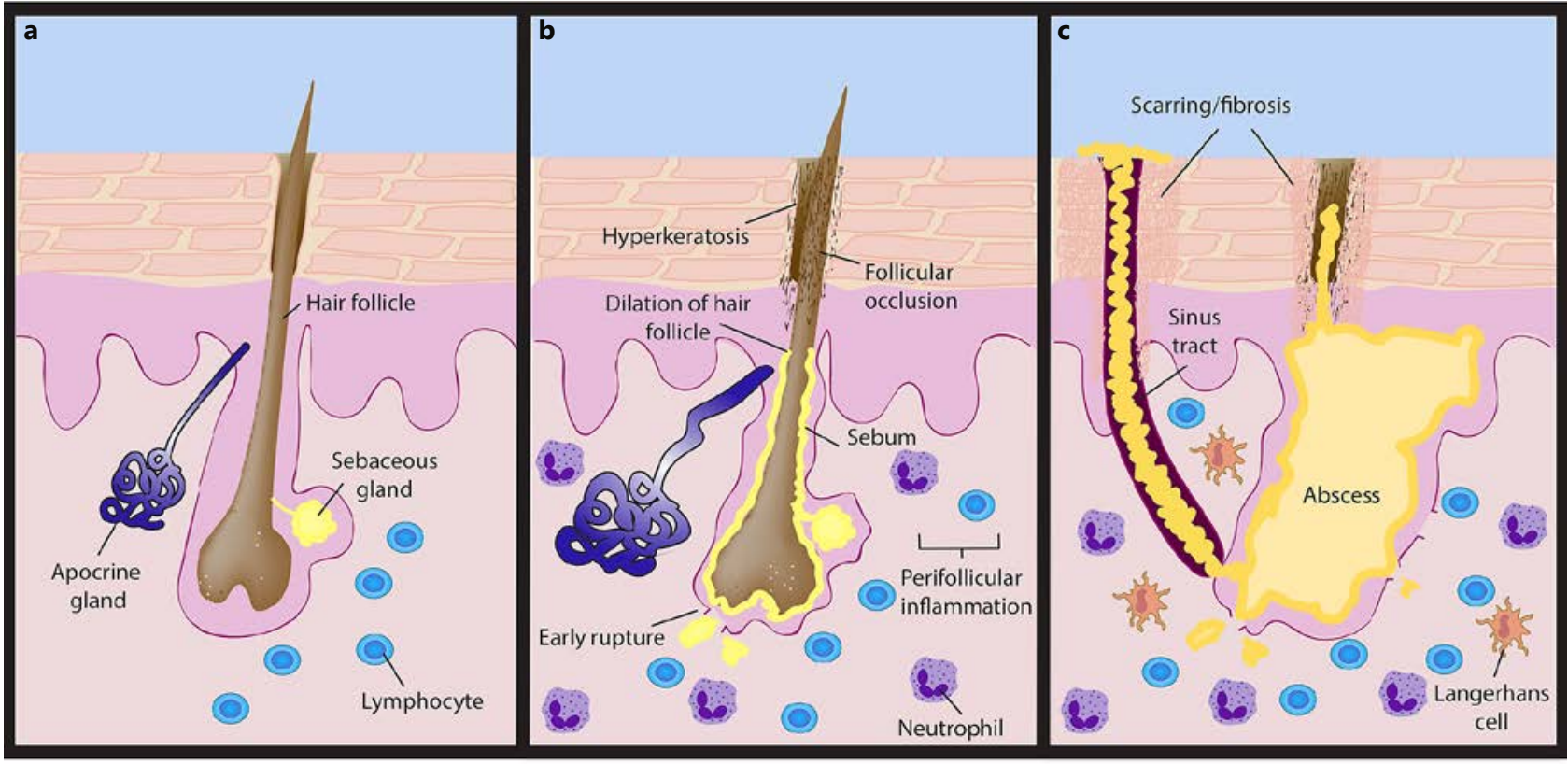

Image created by: Ashley Katherne Cark

Fig. 1. a Normal skin appendageal structure with normal-sized apocrine gland and no inflammation. b Earlystage disease with follicular hyperkeratosis and occlusion, apocrine gland enlargement, follicular dilation and early rupture, and perifollicular inflammation with mixed inflammatory cell infiltrate. c Late-stage disease with increased inflammation, formation of abscess and draining sinus tract, scarring, and fibrosis.

area (for further details, see the online supplementary material; see www.karger.com/doi/10.1159/000486741 for all online suppl. material).

\section{Metabolic Syndrome}

HS and MetS share several major risk factors, including non-Caucasian race (African Americans [AA] and Hispanics) and female gender [11-13]. AA and Hispanics are also significantly less likely to engage in regular exercise compared to Caucasians [14]. The impact of MetS on HS patients is significant, with the burden of MetS comorbidities reported as greater for HS than for psoriasis $[3,15]$. Considering that HS disease severity has been correlated with body mass index, morbid obesity is more common in patients with high versus medium disease burden (37 vs. $22 \%$ ). Nonobese HS patients report more frequent HS remission than obese patients (45 vs. 23\%), and HS onset occurs at younger ages in patients with comorbid MetS. These findings suggest that African and Hispanic patients are at greater risk for MetS, chronic HS, and severer HS $[6,16]$. Studies with larger sample sizes of African and Hispanic populations are needed to further assess this potentially significant relationship (Table 2).

\section{Depression and QoL}

HS commonly has profound psychological and physical effects. HS has been associated with significant disability, embarrassment, and social isolation, as well as decreases in intimate relationships and sexual activity [17, 18], all of which lead to impaired QoL, depression, and anxiety $[7,16]$. Depression is more prevalent in those with higher disease burden than those with medium disease burden (52 vs. 35\%) [6]. HS patients have higher QoL impairment than patients with psoriasis, acne, neoplasms, strokes, and heart transplant candidates $[6,16,17]$. This has serious implications for African and Hispanic populations, who already have broader ranges of psychosocial stressors [19]. A survey that oversampled AA and Hispanics relative to Caucasians found that major depression was most prevalent among Hispanics (11\%) followed by 
Table 1. Summary of study cohorts in studies of hidradenitis suppurativa

\begin{tabular}{|c|c|c|c|c|c|c|c|c|}
\hline Setting & Objective of study & $\begin{array}{l}\text { HS patients } \\
\text { in cohort, } n\end{array}$ & $\begin{array}{l}\text { Percentage } \\
\text { white }\end{array}$ & $\begin{array}{l}\text { Percentage } \\
\text { African American }\end{array}$ & $\begin{array}{l}\text { Percentage } \\
\text { Hispanic }\end{array}$ & $\begin{array}{l}\text { Percentage } \\
\text { other ethnicity }\end{array}$ & $\begin{array}{l}\text { Year of } \\
\text { publi-cat- } \\
\text { ion }\end{array}$ & $\begin{array}{l}\text { Refe- } \\
\text { rence } \\
\text { No. }\end{array}$ \\
\hline Israel & Comorbidities & 3,207 & 0 & None & None & 100 (Israeli) & 2015 & 42 \\
\hline Netherlands & Comorbidities & 106 & Majority & Not reported & Not reported & Not reported & 2016 & 43 \\
\hline Denmark & Comorbidities & 358 & $>96.5$ & Not reported & Not reported & Not reported & 2014 & 3 \\
\hline Denmark & Comorbidities & 5,964 & Majority & Not reported & Not reported & Not reported & 2016 & 44 \\
\hline USA & Comorbidities & 15 & 33.3 & 60 & None & Not reported & 2016 & 45 \\
\hline Denmark & Comorbidities & 462 & 97 & Not reported & Not reported & Not reported & 2016 & 46 \\
\hline USA & Treatment & 76 & Not reported & 81.6 & Not reported & Not reported & 2016 & 29 \\
\hline USA & Prevalence/incidence & 381 & $33+2$ & 65 & Not reported & 2 & 2015 & 5 \\
\hline USA & Prevalence/incidence & 5,410 & 56.2 & 30.1 & Not reported & 12.4 & 2017 & 4 \\
\hline USA & Prevalence/incidence & 268 & 90.3 & Not reported & Not reported & 9.7 & 2013 & 10 \\
\hline USA & Prevalence/incidence & 366 & 25.7 & 54.4 & Not reported & 19.9 & 2014 & 9 \\
\hline USA & Prevalence/incidence & 1,046 & 66.7 & 13.9 & 13.4 & 6 & 2014 & 47 \\
\hline Canada & Demographics & 80 & 75 & Not reported & Not reported & Not reported & 2016 & 7 \\
\hline USA & Demographics & 236 & 77.1 & 22.9 & Not reported & Not reported & 2014 & 18 \\
\hline Czech Republic & Clinical trial & 8 & 50 & None & None & 50 & 2010 & 33 \\
\hline International & Clinical trial & 154 & 71.4 & 18.8 & Not reported & Not reported & 2012 & 34 \\
\hline International & Clinical trial & 307 & 76.2 & 20.2 & Not reported & 3.6 & 2016 & 35 \\
\hline International & Clinical trial & 326 & 83.7 & 8.9 & Not reported & 7.4 & 2016 & 35 \\
\hline Denmark & Clinical trial & 21 & Not reported & Not reported & Not reported & Not reported & 2011 & 36 \\
\hline
\end{tabular}

HS, hidradenitis suppurativa; USA, United States of America.

Table 2. Hidradenitis suppurativa in skin of color: recommendations for clinical care and research

\begin{tabular}{|c|c|}
\hline Issue & Recommendations \\
\hline $\begin{array}{l}\text { Metabolic } \\
\text { syndrome }\end{array}$ & $\begin{array}{l}\text { Studies evaluating the relationship between the metabolic syndrome and skin of color in patients with HS are } \\
\text { needed } \\
\text { Increase surveillance for metabolic syndrome in patients with HS, and vice versa, especially those with skin of color } \\
\text { Encourage lifestyle modifications (e.g., diet, exercise, and smoking cessation) in patients with HS }\end{array}$ \\
\hline $\begin{array}{l}\text { Depression and } \\
\text { quality of life }\end{array}$ & $\begin{array}{l}\text { Studies examining and comparing depression, quality of life, and mental health in the different racial sub- } \\
\text { groups of patients with HS are needed } \\
\text { Increased evaluation of the severity of depression in patients with HS is warranted }\end{array}$ \\
\hline $\begin{array}{l}\text { Socioeconomic } \\
\text { status }\end{array}$ & $\begin{array}{l}\text { Studies examining the relationship between HS, race, and socioeconomic status are needed } \\
\text { Increase social support through HS support groups, HS foundations, educational programs, and access to so- } \\
\text { cial work in HS patients with low socioeconomic status }\end{array}$ \\
\hline Genetics & Genetic studies in HS patients with skin of color are needed \\
\hline $\begin{array}{l}\text { Access to effective } \\
\text { care }\end{array}$ & $\begin{array}{l}\text { Increase HS knowledge and awareness among nondermatologists } \\
\text { Evaluate barrier to access to dermatologists for patients with skin of color, especially those with low socioeco- } \\
\text { nomic status } \\
\text { Initiate early screening for teens and young adults at risk through school and community health programs and } \\
\text { health education classes } \\
\text { Provide longitudinal HS care plans through multidisciplinary centers involving social workers, dieticians, weight } \\
\text { loss counselors, and nursing educations, especially in communities with high prevalence of HS and skin of color }\end{array}$ \\
\hline
\end{tabular}

HS, hidradenitis suppurativa. 
AA (9\%), then Caucasians (8\%) [14]. Factors such as functional limitations, lack of health insurance, and lifestyle factors such as smoking and exercise, all of which varied across racial groups, were believed to contribute to the difference in depression rates [14]. Chronicity of major depressive disorder is higher in AA than Caucasians (57 vs. 39\%). AA are also more likely to rate their depression as severe/very severe and more disabling [20]. Given these findings, African and Hispanic patients with HS may be at greater risk for depression and severer depression, in part because HS has a larger negative impact on their QoL [21]. However, data for these populations are lacking, and research comparing mental health and QoL of HS patients in different racial subgroups is needed (Table 2).

\section{Socioeconomic Status}

HS is reportedly more common in individuals of low SES [8], which is more prevalent in African and Hispanic populations, especially in the USA [14, 19]. Racial differences in SES are also closely associated with racial disparities in health and psychosocial well-being among AA and Hispanics $[14,19]$. This may directly contribute to the higher prevalence of HS in patients with SOC. Low SES is closely associated with MetS, with odds of MetS significantly increased in females with less than 5 years of education $(\mathrm{OR}=2.28 ; 95 \% \mathrm{CI}=$ 1.48-3.51) and unfavorable social class, as described by current occupation ( $\mathrm{OR}=2.59 ; 95 \% \mathrm{CI}=1.32-4.79$ for unemployed females) $[13,22]$. Altogether, these findings suggest a potential relationship between HS, race, SES, MetS, and psychological comorbidities, though additional investigation is needed in this area (Table 2).

\section{Genetics}

Genetics studies have demonstrated an autosomal dominant pattern of familial HS inheritance. HS patients have mutations in genes (NCSTN, PSENEN, PSEN1) that code for subunits of $\gamma$-secretase, which normally cleaves Notch receptor, a transmembrane protein involved in epidermal and follicular development and differentiation $[23,24]$. Notably, a significant number of these studies were conducted in Chinese populations [25-27]. Although 1 study identified a mutation in NCSTN in an African family [28], genetic studies of HS in SOC are lack- ing, despite a higher prevalence of HS in these populations. This is notable since unique genetic mutations may contribute to the varying HS phenotypes seen in women and racial subgroups. AA (83\%) and female (74\%) HS patients in Chicago, IL, were more likely to have recalcitrant HS, progressive symptoms, and require surgical interventions [29], suggesting that patients with SOC may be more likely to have forms of HS that are less treatment responsive. Because genetic factors may be largely responsible, studies comparing genetic variations and epigenetic phenomena among various racial subgroups of HS patients are warranted (Table 2).

\section{Anatomy}

Skin appendageal anatomy appears to differ between racial subgroups. Patients of African descent are reported to have larger, more numerous, and more productive apocrine glands than Caucasians [30,31]. This suggests that African populations may have an anatomical predisposition for both HS and severer HS. Of note, these reports were published before 1965; thus, there is paucity of basic science research in SOC in this area [32]. Investigating potential variations in pilosebaceous unit anatomy and dysfunction among racial subgroups is crucial towards a better understanding how HS differs between these populations (Table 2).

\section{Treatment Response in SOC}

Adalimumab is currently the only approved systemic medication for HS. While clinical trials have demonstrated the efficacy of adalimumab in reducing disease burden, they did not sufficiently examine the clinical response in patients with SOC (Table 1) [33-36]. One study was conducted solely in Caucasian and Romany individuals, while another consisted of $80-88 \%$ Caucasians [33, 35]. A Danish trial did not report race for any participants [36]. Two trials did have cohorts containing 19-20\% AA; however, this still contrasts with results from studies reporting that AA make up to $65 \%$ of patients with HS in the USA, have a 1-year incidence of HS more than double that of Caucasians, and have the highest 1 -year incidence of HS across all age groups [4, 5, 34, 35]. Furthermore, none of the trials reported the percentage of patients that were Hispanic or stratified the responses to adalimumab by race. The majority of the efficacy trials investigating other systemic agents, including etanercept, infliximab, 
anakinra, and ustekinumab, either did not report race or had largely Caucasian cohorts [37-40]. Taken together, this highlights the underrepresentation of non-Caucasian subjects and the need for trials that enroll more HS patients with SOC and stratify results by racial subgroups (Table 2).

\section{Access to Effective Care}

Adding to the aforementioned issues is access to care for patients with low SES and SOC, in whom HS is commonly misdiagnosed and underdiagnosed, and who often quit seeking medical care due to ineffective results $[7,18]$. This may be partly explained by a large proportion of HS patients who are diagnosed or managed by nondermatologists [7, 21]. Dermatologists diagnose HS patients significantly earlier in the disease course $(65 \%$ of HS patients diagnosed by dermatologists were Hurley stage I or II, vs. $35 \%$ for nondermatologists), and are more likely to use medical (almost all visits) and procedural (20\% of visits) treatment for HS compared to other providers [7, 21]. This stresses the need to increase disease awareness among nondermatologists and to improve SOC patient access to dermatologists (Table 2).

In the USA, AA made about one third as many annual dermatology visits per capita as Caucasians, and Hispanics averaged even less $[21,41]$. These reports suggest that HS is underdiagnosed and undertreated in SOC, which can be attributed to the limited access to dermatological care, low SES, and cultural factors [21]. Data from the National Center for Health Statistics suggest that the percentage of visits with HS as the diagnosis in which the patient was AA (23\%) was significantly higher than the percentage of all visits by AA (13\%) [18]. While most patients diagnosed with HS were not AA (77\% Caucasians and other groups combined), AA were significantly over- represented (26\%) in the HS population when emergency department visits were considered [18]. These results allude to the prevalence, disease burden, and lack of effective management of HS in patients with SOC.

\section{Conclusion}

HS is a chronic, disabling disease that disproportionately affects patients with SOC. Due to a constellation of genetic and psychosocial factors, African and Hispanic populations experience severer HS, lower QoL, and more comorbid conditions, including MetS and depression. Despite these issues, there is insufficient research and access to care for HS patients of SOC and low SES. Large, population-based studies are needed to fully understand the prevalence and burden of HS in patients with SOC, delineate the genetic and anatomical factors unique to racial subgroups, and determine whether patients with SOC respond differently to HS therapies. The roles that diet, lifestyle, climate, and health care access play in the natural history of HS also deserve further exploration. Finally, efforts should be made to increase access to care to dermatologists, including early screening for at-risk populations and implementation of longitudinal HS care plans.

\section{Key Message}

Hidradenitis suppurativa disproportionately affects skin of color patients, but research in these populations is lacking.

\section{Disclosure Statement}

Dylan E. Lee, Ashley K. Clark, and Vivian Y. Shi declare that they have no relevant conflict of interest, and no financial interest exists either.

\section{References}

$>1$ Alikhan A, Lynch PJ, Eisen DB: Hidradenitis suppurativa: a comprehensive review. J Am Acad Dermatol 2009;60:539-561; quiz 562533.

2 Cesko E, Korber A, Dissemond J: Smoking and obesity are associated factors in acne inversa: results of a retrospective investigation in 100 patients. Eur J Dermatol 2009;19:490493.

>3 Miller IM, Ellervik C, Vinding GR, Zarchi K, Ibler KS, Knudsen KM, Jemec GB: Association of metabolic syndrome and hidradenitis suppurativa. JAMA Dermatol 2014;150: 1273-1280.

4 Garg A, Lavian J, Lin G, Strunk A, Alloo A: Incidence of hidradenitis suppurativa in the United States: a sex- and age-adjusted population analysis. J Am Acad Dermatol 2017;77: 118-122.

5 Vlassova N, Kuhn D, Okoye GA: Hidradenitis suppurativa disproportionately affects African Americans: a single-center retrospective analysis. Acta Derm Venereol 2015;95:990991.
6 Crowley JJ, Mekkes JR, Zouboulis CC, Scheinfeld N, Kimball A, Sundaram M, Gu Y, Okun MM, Kerdel F: Association of hidradenitis suppurativa disease severity with increased risk for systemic comorbidities. Br J Dermatol 2014;171:1561-1565.

$>7$ Kim WB, Sibbald RG, Hu H, Bashash M, Anooshirvani N, Coutts P, Alavi A: Clinical features and patient outcomes of hidradenitis suppurativa: a cross-sectional retrospective study. J Cutan Med Surg 2016; 20:52-57. 
8 Deckers IE, Janse IC, van der Zee HH, Nijsten T, Boer J, Horvath B, Prens EP: Hidradenitis suppurativa (HS) is associated with low socioeconomic status (SES): a cross-sectional reference study. J Am Acad Dermatol 2016;75: 755-759. e751.

-9 Reeder VJ, Mahan MG, Hamzavi IH: Ethnicity and hidradenitis suppurativa. J Invest Dermatol 2014;134:2842-2843.

-10 Vazquez BG, Alikhan A, Weaver AL, Wetter DA, Davis MD: Incidence of hidradenitis suppurativa and associated factors: a populationbased study of Olmsted County, Minnesota. J Invest Dermatol 2013;133:97-103.

11 Centers for Disease Control and Prevention: Differences in prevalence of obesity among black, white, and Hispanic adults - United States, 2006-2008. MMWR Morb Mortal Wkly Rep 2009;58:740-744.

12 Cosmatos I, Matcho A, Weinstein R, Montgomery MO, Stang P: Analysis of patient claims data to determine the prevalence of hidradenitis suppurativa in the United States. J Am Acad Dermatol 2013;68:412-419.

13 Moore JX, Chaudhary N, Akinyemiju T: Metabolic syndrome prevalence by race/ethnicity and sex in the United States, National Health and Nutrition Examination Survey, 19882012. Prev Chronic Dis 2017; 14:E24.

14 Dunlop DD, Song J, Lyons JS, Manheim LM, Chang RW: Racial/ethnic differences in rates of depression among preretirement adults. Am J Public Health 2003;93:1945-1952.

15 Miller IM: Co-morbidities in inflammatory dermatological diseases. Psoriasis, hidradenitis suppurativa, and cardiovascular risk factors. Dan Med J 2015;62:B5143.

16 Kohorst JJ, Kimball AB, Davis MD: Systemic associations of hidradenitis suppurativa. J Am Acad Dermatol 2015;73:S27-S35.

17 Miller IM, McAndrew RJ, Hamzavi I: Prevalence, risk factors, and comorbidities of hidradenitis suppurativa. Dermatol Clin 2016; 34:7-16.

18 McMillan K: Hidradenitis suppurativa: number of diagnosed patients, demographic characteristics, and treatment patterns in the United States. Am J Epidemiol 2014;179: 1477-1483.

19 Williams DR, Priest N, Anderson N: Understanding associations between race, socioeconomic status and health: patterns and prospects. Health Psychology 2016;35:407-411.

-20 Williams DR, Gonzalez HM, Neighbors H, Nesse R, Abelson JM, Sweetman J, Jackson JS: Prevalence and distribution of major depressive disorder in African Americans, $\mathrm{Ca}$ ribbean blacks, and non-Hispanic whites: results from the National Survey of American Life. Arch Gen Psychiatry 2007;64:305315.

-21 Davis SA, Lin HC, Balkrishnan R, Feldman SR: Hidradenitis Suppurativa Management in the United States: An Analysis of the National Ambulatory Medical Care Survey and MarketScan Medicaid Databases. Skin Appendage Disord 2015;1:65-73.
22 Santos AC, Ebrahim S, Barros H: Gender, socio-economic status and metabolic syndrome in middle-aged and old adults. BMC Public Health $2008 ; 8: 62$

23 Ingram JR: The Genetics of Hidradenitis Sup purativa. Dermatol Clin 2016;34:23-28.

24 Yamamoto N, Tanigaki K, Han H, Hiai H, Honjo T: Notch/RBP-J signaling regulates epidermis/hair fate determination of hair follicular stem cells. Curr Biol 2003;13:333-338.

25 Jiao T, Dong H, Jin L, Wang S, Wang J: A novel nicastrin mutation in a large Chinese family with hidradenitis suppurativa. Br J Dermatol 2013;168:1141-1143.

26 Xu H, Xiao X, Hui Y, Zhang X, He Y, Li C, Wang B: Phenotype of 53 Chinese individuals with nicastrin gene mutations in association with familial hidradenitis suppurativa (acne inversa). Br J Dermatol 2016;174:927-929.

27 Yang JQ, Wu XJ, Dou TT, Jiao T, Chen XB, Min M, Cai SQ, Zheng M: Haploinsufficiency caused by a nonsense mutation in NCSTN underlying hidradenitis suppurativa in a Chinese family. Clin Exp Dermatol 2015;40:916-919.

28 Chen S, Mattei P, You J, Sobreira NL, Hinds GA: Gamma-secretase mutation in an African American family with hidradenitis suppurativa. JAMA Dermatol 2015;151:668-670.

29 Thomas C, Rodby KA, Thomas J, Shay E, Antony AK: Recalcitrant hidradenitis suppurativa: an investigation of demographics, surgical management, bacterial isolates, pharmacologic intervention, and patient-reported health outcomes. Am Surg 2016;82:362-368.

30 Hurley HJ, Shelley WB: The physiology and pharmacology of the apocrine sweat gland; in Hurley HJ, Shelley WB (eds): The Human Apocrine Sweat Gland in Health and Disease. Springfield, Thomas, 1960, pp 22-77.

31 Homma H: On apocrine sweat gland in white and Negro men and women. Bull Johns Hopkins Hosp 1926;38:365-371.

32 Taylor SC, Kelly AP, Dupree NE, Kimball AB, Lawrence RC: Health disparities in arthritis and musculoskeletal and skin diseases - the dermatology session: National Institute of $\mathrm{Ar}$ thritis and Musculoskeletal and Skin Diseases, Bethesda, Maryland, December 15-16, 2000. J Am Acad Dermatol 2002;47:770-773.

33 Arenbergerova M, Gkalpakiotis S, Arenberger P: Effective long-term control of refractory hidradenitis suppurativa with adalimumab after failure of conventional therapy. Int J Dermatol 2010;49:1445-1449.

34 Kimball AB, Kerdel F, Adams D, Mrowietz U, Gelfand JM, Gniadecki R, Prens EP, Schlessinger J, Zouboulis CC, van der Zee $\mathrm{HH}$, Rosenfeld M, Mulani P, Gu Y, Paulson S, Okun M, Jemec GB: Adalimumab for the treatment of moderate to severe hidradenitis suppurativa: a parallel randomized trial. Ann Intern Med 2012;157:846-855.

35 Kimball AB, Okun MM, Williams DA, Gottlieb AB, Papp KA, Zouboulis CC, Armstrong AW, Kerdel F, Gold MH, Forman SB, Korman NJ, Giamarellos-Bourboulis EJ, Crowley JJ, Lynde C, Reguiai Z, Prens EP, Alwawi E,
Mostafa NM, Pinsky B, Sundaram M, Gu Y, Carlson DM, Jemec GB: Two phase 3 trials of adalimumab for hidradenitis suppurativa. $\mathrm{N}$ Engl J Med 2016;375:422-434.

36 Miller I, Lynggaard CD, Lophaven S, Zachariae C, Dufour DN, Jemec GB: A double-blind placebo-controlled randomized trial of adalimumab in the treatment of hidradenitis suppurativa. Br J Dermatol 2011;165:391-398.

37 Blok JL, Li K, Brodmerkel C, Horvatovich P, Jonkman MF, Horvath B: Ustekinumab in hidradenitis suppurativa: clinical results and a search for potential biomarkers in serum. $\mathrm{Br}$ J Dermatol 2016;174:839-846.

38 Pelekanou A, Kanni T, Savva A, Mouktaroudi M, Raftogiannis M, Kotsaki A, GiamarellosBourboulis EJ: Long-term efficacy of etanercept in hidradenitis suppurativa: results from an open-label phase II prospective trial. Exp Dermatol 2010;19:538-540.

39 Grant A, Gonzalez T, Montgomery MO, Cardenas V, Kerdel FA: Infliximab therapy for patients with moderate to severe hidradenitis suppurativa: a randomized, doubleblind, placebo-controlled crossover trial. J Am Acad Dermatol 2010;62:205-217.

40 Tzanetakou V, Kanni T, Giatrakou S, Katoulis A, Papadavid E, Netea MG, Dinarello CA, van der Meer JWM, Rigopoulos D, GiamarellosBourboulis EJ: Safety and efficacy of anakinra in severe hidradenitis suppurativa: a randomized clinical trial. JAMA Dermatol 2016;152: 52-59.

41 Davis SA, Narahari S, Feldman SR, Huang W, Pichardo-Geisinger RO, McMichael AJ: Top dermatologic conditions in patients of color: an analysis of nationally representative data. J Drugs Dermatol 2012;11:466-473.

-42 Shalom G, Freud T, Harman-Boehm I, Polishchuk I, Cohen AD: Hidradenitis suppurativa and metabolic syndrome: a comparative cross-sectional study of 3,207 patients. Br J Dermatol 2015;173:464-470.

43 Vossen AR, van der Zee HH, Onderdijk AJ, Boer J, Prens EP: Hidradenitis suppurativa is not associated with the metabolic syndrome based on body type: a cross-sectional study. J Dermatol 2017;44:154-159.

44 Egeberg A, Gislason GH, Hansen PR: Risk of major adverse cardiovascular events and allcause mortality in patients with hidradenitis suppurativa. JAMA Dermatol 2016;152:429434.

45 Kamal N, Cohen BL, Buche S, Delaporte E, Colombel JF: Features of patients with Crohn's disease and hidradenitis suppurativa. Clin Gastroenterol Hepatol 2016;14:71-79.

46 Miller IM, Rytgaard H, Mogensen UB, Miller E, Ring HC, Ellervik C, Jemec GB: Body composition and basal metabolic rate in hidradenitis suppurativa: a Danish population-based and hospital-based cross-sectional study. J Eur Acad Dermatol Venereol 2016;30:980-988.

47 Kim GE, Shlyankevich J, Kimball AB: The validity of the diagnostic code for hidradenitis suppurativa in an electronic database. $\mathrm{Br} \mathrm{J}$ Dermatol 2014;171:338-342. 